\title{
Cervical compensatory alignment changes following correction of adult thoracic deformity: a multicenter experience in 57 patients with a 2-year follow-up
}

\author{
Taemin Oh, BA, ${ }^{1}$ Justin K. Scheer, BS, ${ }^{1}$ Robert Eastlack, MD, ${ }^{2}$ Justin S. Smith, MD, PhD, ${ }^{3}$ \\ Virginie Lafage, PhD, ${ }^{4}$ Themistocles S. Protopsaltis, MD, ${ }^{4}$ Eric Klineberg, MD, ${ }^{5}$ \\ Peter G. Passias, MD, ${ }^{4}$ Vedat Deviren, MD, ${ }^{6}$ Richard Hostin, MD, ${ }^{7}$ Munish Gupta, MD, ${ }^{5}$ \\ Shay Bess, MD, ${ }^{8}$ Frank Schwab, MD, ${ }^{4}$ Christopher I. Shaffrey, MD, ${ }^{3}$ Christopher P. Ames, MD, ${ }^{9}$ \\ and the International Spine Study Group
}

\begin{abstract}
1'Department of Neurological Surgery, Northwestern University, Feinberg School of Medicine, Chicago, Illinois; ${ }^{2}$ Scripps Clinic, San Diego; ${ }^{5}$ Department of Orthopaedic Surgery, University of California, Davis, Sacramento; Departments of ${ }^{6}$ Orthopaedic Surgery and ${ }^{9}$ Neurological Surgery, University of California, San Francisco, California; ${ }^{3}$ Department of Neurosurgery, University of Virginia Health System, Charlottesville, Virginia; ${ }^{4}$ Department of Orthopaedic Surgery, NYU Hospital for Joint Diseases, New York, New York; ' ${ }^{7}$ Department of Orthopaedic Surgery, Baylor Scoliosis Center, Plano, Texas; and ${ }^{8}$ Rocky Mountain Hospital for Children, Denver, Colorado
\end{abstract}

OBJECT Alignment changes in the cervical spine that occur following surgical correction for thoracic deformity remain poorly understood. The purpose of this study was to evaluate such changes in a cohort of adults with thoracic deformity treated surgically.

METHODS The authors conducted a multicenter retrospective analysis of consecutive patients with thoracic deformity. Inclusion criteria for this study were as follows: corrective osteotomy for thoracic deformity, upper-most instrumented vertebra (UIV) between T-1 and T-4, lower-most instrumented vertebra (LIV) at or above L-5 (LIV $\geq$ L-5) or at the ilium (LIVilium), and a minimum radiographic follow-up of 2 years. Sagittal radiographic parameters were assessed preoperatively as well as at 3 months and 2 years postoperatively, including the C-7 sagittal vertical axis (SVA), C2-7 cervical lordosis (CL), C2-7 SVA, T-1 slope (T1S), T1S minus CL (T1S-CL), T2-12 thoracic kyphosis (TK), apical TK, lumbar lordosis (LL), pelvic incidence (PI), PI-LL, pelvic tilt (PT), and sacral slope (SS).

RESULTS Fifty-seven patients with a mean age of $49.1 \pm 14.6$ years met the study inclusion criteria. The preoperative prevalence of increased $\mathrm{CL}\left(\mathrm{CL}>15^{\circ}\right)$ was $48.9 \%$. Both 3-month and 2-year apical TK improved from baseline $(\mathrm{p}<$

\footnotetext{
ABBREVIATIONS ASD = adult spinal deformity; $C L=$ cervical lordosis; $\mathrm{LIV}=$ lower-most instrumented vertebra; $\mathrm{LL}$ =lumbar lordosis; $\mathrm{PI}=$ pelvic incidence; $\mathrm{PSO}=$ pedicle subtraction osteotomy; PT = pelvic tilt; SPI = spinopelvic inclination; SS = sacral slope; SVA = sagittal vertical axis; T1S = T-1 slope; TK = thoracic kyphosis; UIV = uppermost instrumented vertebra; VCR = vertebral column resection; $3 \mathrm{CO}=3$-column osteotomy.

SUBMITTED August 12, 2014. ACCEPTED October 21, 2014.

INCLUDE WHEN CITING Published online March 20, 2015; DOI: 10.3171/2014.10.SPINE14829.

DISCLOSURE The International Spine Study Group Foundation, through which this study was conducted, is funded through research grants from DePuy Spine and individual donations. Dr. Klineberg has received speaker's fees from DePuy Synthes and AOSpine and has received clinical or research support from OREF, DePuy Synthes, and AOSpine for the study described. Dr. Bess is a consultant for K2 Medical and Allosource; has received clinical or research support from DePuy Synthes Spine for the study described; and has received support from Medtronic for non-study-related clinical or research effort. Dr. Ames is a consultant for DePuy, Stryker, and Medtronic; has direct stock ownership in Doctors Research Group and Baxano Surgical; holds a patent with Fish \& Richardson, P.C.; and has received royalties from Aesculap and Biomet Spine. Dr. Lafage has direct stock ownership in and is an employee of Nemaris Inc.; has been a speaker for MSD, K2 Medical, DePuy, and NuVasive; and has received support from DePuy, SRS, ISSG, and NIH for non-study-related clinical or research effort. Dr. Schwab has direct stock ownership in Nemaris Inc.; holds a patent with MSD, K2 Medical, NuVasive, and Nemaris Inc.; is a consultant for MSD, DePuy, K2 Medical, and Medicrea; has been a speaker for MSD, Nemaris Inc., and K2 Medical; and has received support from DePuy, MSD, and AO for non-study-related clinical or research effort. Dr. Smith is a consultant for Biomet, NuVasive, Cerapedics, DePuy, and Medtronic; has received clinical or research support from DePuy/ISSG for the study described; has received support from DePuy/ISSG for non-study-related clinical or research effort; and has received royalties from Biomet. Dr. Gupta has direct stock ownership in Johnson \& Johnson, Proctor \& Gamble, Pfizer, and Pioneer; has received royalties from DePuy; and is a consultant for Medtronic, Medicrea, DePuy Synthes, and Orthofix. Dr. Deviren is a consultant for NuVasive, Guidepoint, and Stryker. Dr. Shaffrey is a consultant for Biomet, Globus, Medtronic, NuVasive, and Stryker; has direct stock ownership in NuVasive; and holds patents with and receives royalties from Biomet, Medtronic, and NuVasive. Dr. Eastlack is a consultant for NuVasive, Alphatec, Don Joy, DePuy/Synthes, Aesculap, Stryker, Invuity, Carevature, DiFusion, and K2 Medical; holds patents with Invuity, NuTech, and Globus; has direct stock ownership in NuVasive and Alphatec; has received clinical or research support from NuVasive and Pioneer/RTI for the study described; and is part of the speaker's bureau for Eli Lilly. Dr. Hostin is a consultant for DePuy Spine and has received clinical or research support from NuVasive, Seeger, DJO, DePuy Spine, and K2 Medical for the study described. Dr. Protopsaltis is a consultant for Medicrea, Biomet Spine, and DePuy Synthes Spine and has received support from Zimmer Spine for non-study-related clinical or research effort.
} 
0.05 , statistically significant). At the 2-year follow-up, only the C2-7 SVA increased significantly from baseline $(p=0.01)$, whereas LL decreased from baseline $(p<0.01)$. The prevalence of increased $C L$ was $35.3 \%$ at 3 months and $47.8 \%$ at 2 years, which did not represent a significant change. Postoperative cervical alignment changes were not significantly different from preoperative values regardless of the LIV (LIV $\geq$ L- 5 or LIV-ilium, $p>0.05$ for both). In a subset of patients with a maximum $\mathrm{TK} \geq 60^{\circ}$ (35 patients) and 3-column osteotomy (38 patients), no significant postoperative cervical changes were seen.

CONCLUSION Increased CL is common in adult spinal deformity patients with thoracic deformities and, unlike after lumbar corrective surgery, does not appear to normalize after thoracic corrective surgery. Cervical sagittal malalignment (C2-7 SVA) also increases postoperatively. Surgeons should be aware that spontaneous cervical alignment normalization might not occur following thoracic deformity correction.

http://thejns.org/doi/abs/10.3171/2014.10.SPINE14829

KEY WORDS adult spinal deformity; cervical deformity; thoracic deformity; sharp angular kyphosis; reciprocal change; 3-column osteotomy

A DULT spinal deformity (ASD) is a pathological condition defined as spinal malalignment in the axial, coronal, or sagittal plane and is derivative of congenital, iatrogenic, degenerative, or idiopathic etiology. ${ }^{30}$ The restoration of sagittal alignment, as established by the sagittal vertical axis (SVA; target $<5 \mathrm{~cm}$ ) and pelvic tilt $\left(\mathrm{PT}\right.$; target $<20^{\circ}$ ) on sagittal radiography, is important in surgical deformity correction. ${ }^{6,21,22}$ Although coronal plane correction also has clinical relevance, sagittal corrections appear to have greater importance,, 5 principally because sagittal radiographic parameters have consistently been associated with physical disability, emotional disability, and diminished health-related quality of life. $2,5,6,10,13,20,23,26$

Sagittal cervical malalignment merits proper consideration since it has been associated with significantly worse patient outcomes. In a recent cohort study of 113 patients, Tang et al. demonstrated that cervical malalignment correlates with physical disability. ${ }^{26}$ In another study by Villavicencio et al., less disability was seen among the patients demonstrating postoperative improvements in cervical sagittal alignment. ${ }^{27}$ In practice, achieving optimal correction of cervical malalignment can be challenging. Patients with ASD can present with concomitant deformities given that compensatory changes within adjacent areas (for example, pelvic retroversion, increased cervical lordosis [CL]) can occur as the patients attempt to maintain upright alignment, normal gait, and horizontal gaze..$^{10,11,19}$ Additionally, one potential consequence of surgical instrumentation is that unfused regions of adjacent spine can demonstrate dynamic changes postoperatively, a phenomenon referred to as "reciprocal change."

Reciprocal changes in neighboring unfused segments have been described following instrumentation and fusion, and these relationships carry compelling implications for patient management. At times, reciprocal changes have been shown to improve patient outcomes, as evidenced by spontaneous correction of increased CL following lumbar pedicle subtraction osteotomy (PSO) ${ }^{25}$ Occasionally, however, the converse has been observed. In a study conducted by Lafage et al., for example, 34 patients underwent lumbar PSO, but 18 patients had reciprocal increases in thoracic kyphosis (TK) that led to poor sagittal alignment. ${ }^{9}$

Improving the understanding of such reciprocal relationships will likely form a critical component in the future management of patients with ASD. However, studies thus far have focused disproportionately on reciprocal changes following lumbar deformity correction, with fewer reports of reciprocal changes following thoracic deformity correction. ${ }^{8,17}$ More specifically, cervical changes following thoracic deformity surgery have yet to be fully characterized, and this knowledge gap provided the impetus for the current study, in which we endeavored to evaluate changes in spinal alignment following the correction of thoracic deformity. We hypothesized that thoracic deformity correction would lead to significant radiographic improvement in cervical and spinopelvic alignment.

\section{Methods \\ Patient Population}

We conducted a retrospective radiographic review of a large, multiinstitutional database of consecutively treated ASD patients, which had been collected with institutional review board approval at each institution. Inclusion criteria for this primary database were 1) an age $\geq 18$ years and 2) a diagnosis of spinal deformity (scoliosis Cobb angle $\geq$ $20^{\circ}$, SVA $\geq 5 \mathrm{~cm}, \mathrm{PT} \geq 25^{\circ}$, or TK $\geq 60^{\circ}$ ). Neuromuscular spinal deformities and patients with active infections or malignancy were excluded. For the present study, additional inclusion criteria were as follows: 1) at least 1 corrective osteotomy for a primary thoracic deformity, 2) upper-most instrumented vertebra (UIV) between T-1 and $\mathrm{T}-4,3)$ lower-most instrumented vertebra (LIV) at L-5 or above (LIV $\geq \mathrm{L}-5$ ) or at the ilium (LIV-ilium), and 4) a minimum radiographic follow-up of 2 years. Patients who had osteotomies extending into the thoracic spine from the correction of a primary lumbar deformity and those who had undergone lumbar 3-column osteotomies were excluded.

\section{Data Collection and Radiographic Assessment}

Data pertaining to patient demographics, surgical osteotomy type, and radiographic parameters were collected. The surgical osteotomies included Smith-Petersen and 3-column osteotomies (3COs), the latter involving either PSO or vertebral column resection (VCR).

Full-length, free-standing, 36" cassette, lateral spine radiographs were obtained preoperatively and at the 3 -month and 2-year postoperative time points in accor- 
dance with established standards for proper radiographic evaluation. ${ }^{1}$ Outcome measures were sagittal radiographic parameters at the time of follow-up, which were analyzed using validated software (Spineview, ENSAM, Laboratory of Biomechanics). ${ }^{4,18}$ All radiographic measurements were performed at a central location using conventional techniques. . $^{15,19,24}$

Radiographic parameters for regional and global spinal alignment were represented as follows: C2-7 SVA (C-2 plumb line relative to $\mathrm{C}-7$ ), $\mathrm{CL}$ (Cobb angle between the superior endplate of C-2 and the inferior endplate of C-7), T-1 slope (T1S), and T1S minus CL (T1S-CL) for cervical alignment; TK (T2-12; Cobb angle between the superior endplate of T-2 and the inferior endplate of T-12) and apical TK for thoracic alignment (maximal angle for the apex of the sagittal thoracic curve); lumbar lordosis (LL; Cobb angle between the superior endplates of L-1 and the sacrum), PT, pelvic incidence (PI), sacral slope (SS), and PI-LL mismatch for spinopelvic alignment; and C-7 SVA (C-7 plumb line relative to S-1), T-1 spinopelvic inclination (T1SPI), and T9SPI for global sagittal alignment. Cervical malalignment was classified as kyphosis $\left(\mathrm{CL}<0^{\circ}\right)$, increased $\mathrm{CL}\left(\mathrm{CL}>15^{\circ}\right),{ }^{25}$ and cervical sagittal malalignment $(\mathrm{C} 2-7 \mathrm{SVA}>4 \mathrm{~cm}){ }^{26}$

\section{Statistical Analysis}

Continuous variables for summary statistics were described with mean \pm standard deviation estimates. Radiographic parameters were compared between baseline and postoperative values, and differences were assessed using the Wilcoxon signed-rank test. Contingency analysis for categorical variables was conducted using the chi-square test. Subgroup analysis was done on patients with an LIV $\geq \mathrm{L}-5$, LIV-ilium, maximum $\mathrm{TK} \geq 60^{\circ}$, and those who underwent $3 \mathrm{CO}$ (that is, PSO and VCR). The threshold for statistical significance was $p<0.05$. All analyses were performed using Intercooled Stata, version 12 (StataCorp.).

\section{Results}

\section{Patient Population}

Ninety-seven patients with ASD were treated for thoracic deformity and thus were reviewed further for this study. Forty patients were excluded for not having a UIV between T- 1 and T- 4 and not having an LIV $\geq$ L- 5 or at the ilium. Overall, 57 patients (44 females, 13 males) met all criteria for inclusion in this analysis. Demographics are summarized in Tables 1 and 2. The mean patient age was $49.1 \pm 14.6$ years (range $21-80$ years), and the mean body mass index was $27.8 \pm 7.3 \mathrm{~kg} / \mathrm{m}^{2}$ (range $18-57 \mathrm{~kg} / \mathrm{m}^{2}$ ). Thirty-five patients presented with a maximum TK angle $\geq 60^{\circ}$. Nineteen patients underwent Smith-Petersen osteotomy, and the 3 most common osteotomy levels were T-8 (95\%), T-7 (89\%), and T-9 (89\%). Thirty-eight patients underwent $3 \mathrm{CO}$, of which 27 were VCR and 11 were PSO. In the VCR group, osteotomies were most commonly performed at T-9 (22\%), T-7 (15\%), and T-10 (15\%). In the PSO group, osteotomies were most commonly performed at T-7 (27\%), T-8 (18\%), T-11 (18\%), and T-12 (18\%). The mean preoperative radiographic values did not demonstrate significant global sagittal malalignment in the over-
TABLE 1. Summary of demographics for 57 ASD patients with thoracic deformity

\begin{tabular}{cc}
\hline \multicolumn{1}{c}{ Factor } & No. \\
\hline Mean age in yrs (range) & $49.1 \pm 14.6(21-80)$ \\
\hline Sex (\%) & $13(23)$ \\
\hline Male & $43(77)$ \\
\hline Female & $27.8 \pm 7.3(18-57)$ \\
\hline BMI in kg/m ${ }^{2}$ (range) & $11(19)$ \\
\hline UIV termination level (\%) & $26(46)$ \\
\hline T-1 & $15(26)$ \\
\hline T-2 & $5(9)$ \\
\hline T-3 & $1(2)$ \\
\hline T-4 & $2(4)$ \\
\hline LIV termination level (\%) & $5(9)$ \\
\hline T-11 & $11(19)$ \\
\hline T-12 & $9(16)$ \\
\hline L-1 & $11(19)$ \\
\hline L-2 & $18(32)$ \\
\hline L-3 & $19(33)$ \\
\hline L-4 & $27(47)$ \\
\hline llium & $11(19)$ \\
\hline Osteotomy type (\%) &
\end{tabular}

$\mathrm{BMI}=$ body mass index $; \mathrm{SPO}=$ Smith-Petersen osteotomy .

all cohort: C-7 SVA, $7.6 \pm 49.9 \mathrm{~mm}$; T1SPI, $-5.0^{\circ} \pm 4.8^{\circ}$; and T9SPI, $-16.2^{\circ} \pm 6.8^{\circ}$.

\section{Cervical Radiographic Outcomes}

Among the entire study cohort, the mean preoperative cervical parameters revealed cervical malalignment, with increased CL $\left(18.5^{\circ} \pm 19.7^{\circ}\right)$ and cervical sagittal malalignment (41.7 $\pm 18.4 \mathrm{~mm}$ ) both evident (Table 3; Fig. 1).

TABLE 2. Osteotomy level in 57 ASD patients with thoracic deformity

\begin{tabular}{cccc}
\hline & \multicolumn{3}{c}{ No. (\%) } \\
\cline { 2 - 4 } Osteotomy Level & SPO & VCR & PSO \\
\hline T-2 & $1(5)$ & $0(0)$ & $0(0)$ \\
\hline T-3 & $2(11)$ & $1(4)$ & $0(0)$ \\
\hline T-4 & $6(32)$ & $2(7)$ & $0(0)$ \\
\hline T-5 & $11(58)$ & $1(4)$ & $1(9)$ \\
\hline T-6 & $15(79)$ & $2(7)$ & $0(0)$ \\
\hline T-7 & $17(89)$ & $4(15)$ & $3(27)$ \\
\hline T-8 & $18(95)$ & $1(4)$ & $2(18)$ \\
\hline T-9 & $17(89)$ & $6(22)$ & $1(9)$ \\
\hline T-10 & $16(84)$ & $4(15)$ & $0(0)$ \\
\hline T-11 & $11(58)$ & $3(11)$ & $2(18)$ \\
\hline T-12 & $8(42)$ & $3(11)$ & $2(18)$ \\
\hline
\end{tabular}




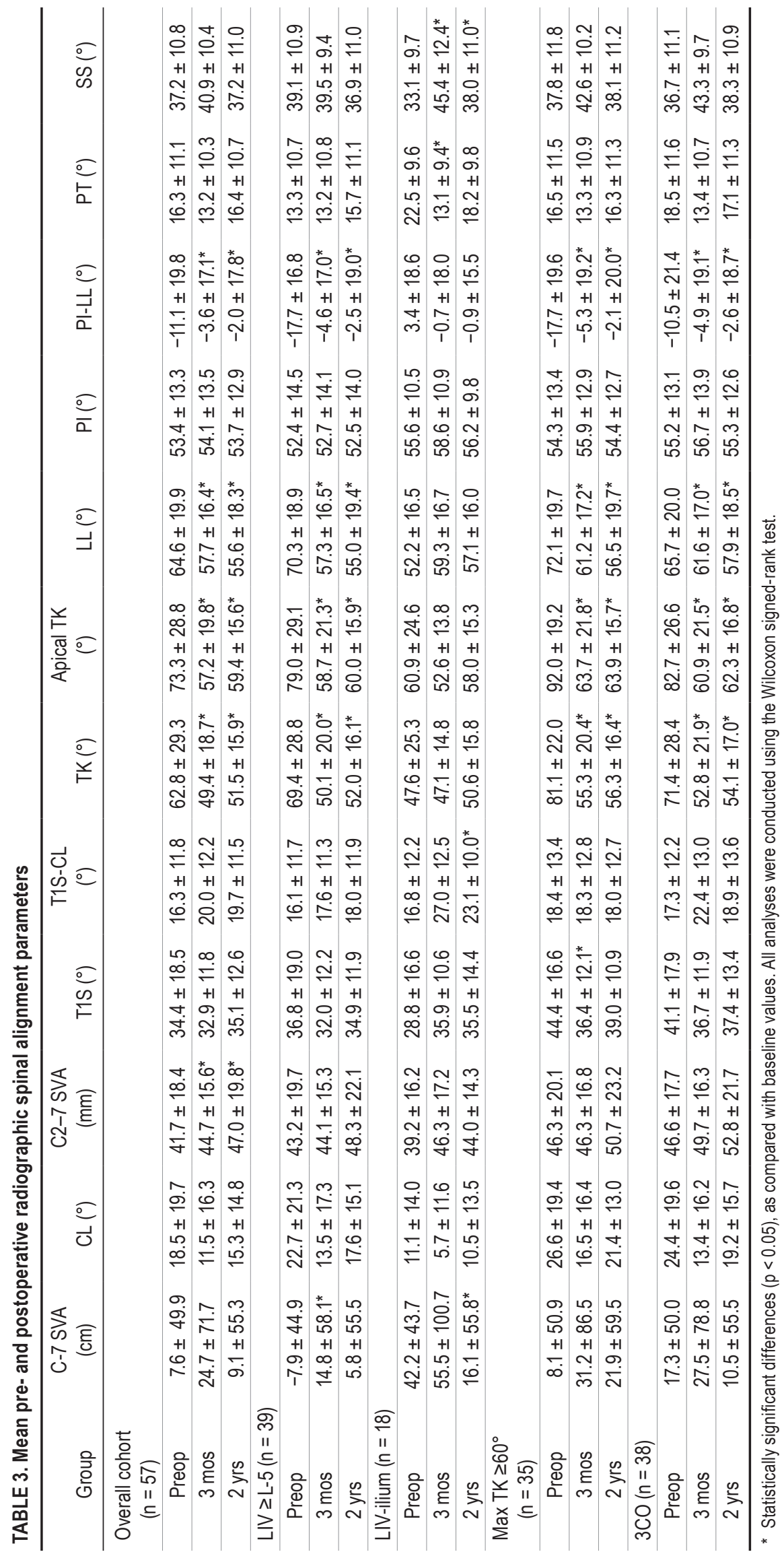




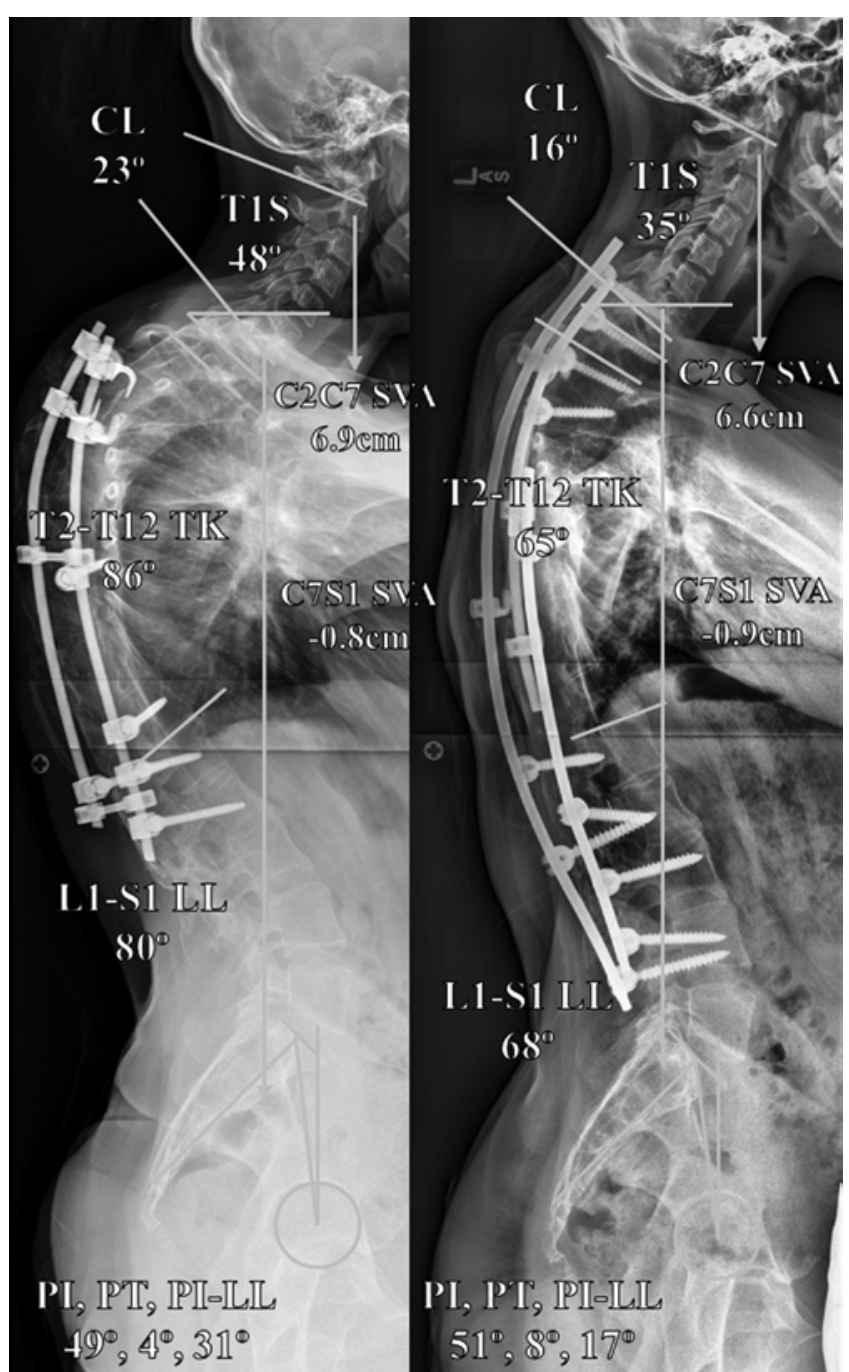

FIG. 1. Case example. Preoperative (left) and postoperative (right) sagittal radiographs showing measurements. Note the increased preoperative $\mathrm{CL}\left(>15^{\circ}\right)$ that slightly decreases and the persistent large $\mathrm{C} 2-7$ SVA in the setting of normal lumbopelvic parameters. $\mathrm{CL}=\mathrm{C} 2-7$ cervical lordosis.

Rates of preoperative cervical kyphosis, cervical sagittal malalignment, and increased CL were $17.8 \%, 47.8 \%$, and $48.9 \%$, respectively (Table 4). Following thoracic deformity correction, significant changes were seen in the $\mathrm{C} 2-7$ SVA at both 3 months and 2 years postoperatively $(\mathrm{p}<$ 0.05 for both) but not in the corresponding rates of cervical malalignment ( $p>0.05$ for both). Rates for cervical deformity correction at 2 years postoperatively were $29 \%, 26 \%$, and $21 \%$ for cervical kyphosis, cervical sagittal malalignment, and increased CL, respectively (Table 5). Among patients undergoing distal fusion at or above L-5 versus at the ilium, no significant cervical changes in CL or C2-7 SVA were observed at 3 months or 2 years postoperatively ( $p>0.05$ for all). Among patients with maximum TK $\geq 60^{\circ}$ or those undergoing a $3 \mathrm{CO}$, cervical parameters did not significantly change at either time point ( $p>0.05$ for all). Several patients developed new-onset cervical deformity: among those without concurrent baseline cervical spine deformity, the incidence of new cervi-
TABLE 4. Preoperative and postoperative rates of cervical spine deformity differences compared to baseline

\begin{tabular}{llc}
\hline \multicolumn{1}{c}{ Factor } & Rate (no./total) & p Value \\
\hline Cervical kyphosis & & \\
\hline Preop & $17.8 \%(8 / 45)$ & \\
\hline 3 mos & $28.6 \%(10 / 35)$ & 0.25 \\
\hline 2 yrs & $19.6 \%(9 / 46)$ & 0.83 \\
\hline C2-7 SVA $>4 \mathrm{~cm}$ & & \\
\hline Preop & $47.8 \%(22 / 46)$ & \\
\hline 3 mos & $65.7 \%(23 / 35)$ & 0.11 \\
\hline 2 yrs & $61.7 \%(29 / 47)$ & 0.18 \\
\hline Increased CL $\left(C L>15^{\circ}\right)$ & & \\
\hline Preop & $48.9 \%(22 / 45)$ & \\
\hline 3 mos & $35.3 \%(12 / 34)$ & 0.23 \\
\hline 2 yrs & $47.8 \%(22 / 46)$ & 0.92 \\
\hline Increased CL $+C 2-7$ SVA $>4 \mathrm{~cm}$ & $6.8 \%(3 / 44)$ & \\
\hline Preop & $14.3 \%(5 / 35)$ & 0.27 \\
\hline 3 mos & $8.7 \%(4 / 46)$ & 0.74 \\
\hline 2 yrs
\end{tabular}

* All analyses were conducted using the chi-square test. A p $<0.05$ was considered statistically significant.

cal deformity at the 2-year follow-up was $12 \%, 55 \%$, and $24 \%$ for cervical kyphosis, cervical sagittal malalignment, and increased CL, respectively (Table 6).

\section{Thoracic Radiographic Outcomes}

The mean preoperative thoracic parameters within the entire cohort revealed thoracic sagittal malalignment (TK: $62.8^{\circ} \pm 29.3^{\circ}$; Table 3). After thoracic osteotomy, the mean TK and apical TK significantly decreased from baseline at both the 3-month and 2-year follow-ups $(\mathrm{p}<0.05$ for both; Fig. 1). Among patients with an LIV $\geq$ L-5, the mean TK and apical TK were significantly lower at 3 months and 2 years postoperatively ( $\mathrm{p}<0.05$ for both). In contrast, patients with an LIV-ilium did not show statistically significant changes in the mean kyphosis angle or apical TK ( $p>0.05$ for both). Patients with a maximum TK $\geq 60^{\circ}$ or those who underwent $3 \mathrm{CO}$ showed significant decreases in TK and apical TK at the 3-month and 2-year follow-ups ( $p<0.05$ for both).

\section{Spinopelvic Radiographic Outcomes}

At baseline, global and pelvic sagittal malalignment were not seen, although there was significant TK (Fig. 1). However, 3-month and 2-year postoperative radiographic values revealed significant changes in LL and PI-LL (p $<0.05$ for both; Table 3). Patients with an LIV $\geq$ L-5 had significantly reduced LL and PI-LL at 3 months and at 2 years, as compared with preoperative values $(\mathrm{p}<0.01$ for both). Patients with an LIV-ilium had an increased SS at 3 months and at 2 years, again as compared with preoperative values ( $p<0.05$ for both). Following surgery, the mean values for LL and PI-LL were also significantly lower among patients with a maximum $\mathrm{TK} \geq 60^{\circ}$ and those with $3 \mathrm{CO}(\mathrm{p}<0.05$ for both). 
TABLE 5. Spontaneous correction of preoperative cervical malalignment and persistent malalignment among those presenting with concomitant cervical malalignment and thoracic deformity

\begin{tabular}{llcccc}
\hline & \multicolumn{3}{c}{ Deformity Rates (no./total [\%]) } \\
\cline { 2 - 3 } \multicolumn{1}{c}{ Factor } & \multicolumn{2}{c}{3 Mos } & & \multicolumn{2}{c}{2 Yrs } \\
\cline { 2 - 3 } \cline { 5 - 6 } & Corrected & Persistent & & Corrected & Persistent \\
\hline Cervical kyphosis $(n=8)$ & $3 / 7(43)$ & $4 / 7(57)$ & & $2 / 7(29)$ & $5 / 7(71)$ \\
\hline C2-7 SVA >4 cm $(n=22)$ & $2 / 14(14)$ & $12 / 14(86)$ & & $5 / 19(26)$ & $14 / 19(74)$ \\
\hline Increased CL $(n=22)$ & $4 / 12(33)$ & $8 / 12(67)$ & & $4 / 19(21)$ & $15 / 19(79)$ \\
\hline Increased CL + C2-7 SVA $>4 \mathrm{~cm}(\mathrm{n}=3)$ & $2 / 3(67)$ & $1 / 3(33)$ & & $1 / 2(50)$ & $1 / 2(50)$ \\
\hline
\end{tabular}

\section{Discussion}

Spontaneous reciprocal changes in the cervical and thoracic spines have been shown following lumbar corrective surgery. Klineberg et al. showed a reciprocal $+13^{\circ}$ change in $\mathrm{TK}^{*}$, Jang et al. treated 53 patients for lumbar degenerative kyphosis and showed spontaneous correction of TK from $1.1^{\circ}$ to $17.6^{\circ}$, with greater corrections of LL leading to incremental improvements in TK $;^{7}$ and, perhaps most importantly, as reported by Smith et al., increased CL spontaneously corrected following lumbar PSO. ${ }^{25} \mathrm{Re}-$ ciprocal changes following thoracic deformity correction have been reported less often. In Klineberg et al.'s series of 29 thoracic PSOs, the authors revealed a reciprocal $8^{\circ}$ reduction in LL. ${ }^{8}$ Peelle et al. reported $50 \%$ spontaneous correction of the lumbar curve in the coronal plane and $68 \%$ on side-bending radiographs following thoracic fusion for scoliosis. ${ }^{17}$ And although they conducted a study on adolescent idiopathic scoliosis patients, Newton et al. demonstrated that when these patients were treated using thoracic fusion with an LIV of T11-L1, LL decreased postoperatively. ${ }^{14}$

Our study is the first attempt to characterize radiographic changes in both cervical and lumbar regions following thoracic osteotomies. Given evidence in the literature, we hypothesized that thoracic deformity correction would lead to reciprocal improvements in cervical and spinopelvic radiographic parameters. The results of our analysis indicated that some significant reciprocal changes in the cervical spine do occur postoperatively, as evidenced by the 5.3-mm increase in the C2-7 SVA at 2 years; however, this increase suggested a possible worsening of cervical sagittal alignment. Furthermore, the mean 2-year postoperative values for $\mathrm{CL}\left(15.3^{\circ} \pm 14.8^{\circ}\right)$ and C2-7 SVA (47.0 $\pm 19.8 \mathrm{~mm}$ ) suggested a lack of consistent improvement in

TABLE 6. New postoperative cervical deformity among patients presenting without baseline cervical deformity

\begin{tabular}{lcc}
\hline & \multicolumn{2}{c}{ Deformity Rates (no./total [\%]) } \\
\cline { 2 - 3 } \multicolumn{1}{c}{ Factor } & 3 Mos & 2 Yrs \\
\hline Cervical kyphosis & $5 / 23(22)$ & $4 / 33(12)$ \\
\hline C2-7 SVA $>4 \mathrm{~cm}$ & $9 / 16(56)$ & $12 / 22(55)$ \\
\hline Increased CL & $2 / 17(12)$ & $5 / 21(24)$ \\
\hline Increased CL + C2-7 SVA $>4 \mathrm{~cm}$ & $4 / 26(15)$ & $3 / 37(8)$ \\
\hline
\end{tabular}

CL and the persistence of sagittal cervical malalignment, respectively. Rates of cervical deformity also did not significantly change from baseline, and several patients even developed a new cervical spine deformity after undergoing thoracic osteotomy. On the other hand, in the lumbar spine, significant changes were observed in the form of improved PI-LL. No other changes were seen in the lumbar parameters.

Collectively, these results suggested that thoracic osteotomies have some impact on postoperative cervical or spinopelvic alignment. To validate these findings, we conducted several subgroup analyses. In the first subgroup analysis, for two reasons we aimed to ascertain whether the level of distal fusion was a contributory factor in reciprocal change. From a mechanistic standpoint, patients with lower instrumentation reaching the ilium should be more susceptible to reciprocal changes in the cervical spine given the operative fixation of spinopelvic alignment. Theoretically, these patients would be unable to compensate for thoracic deformity correction in the lumbar spine and would have increased difficulty in the pelvis, thus increasing the likelihood for change to occur in the cervical spine. Additionally, literature evidence has pointed to fusion levels influencing the directionality of reciprocal change, with one study showing that thoracic PSOs with lumbar fusion increased postoperative LL while those without resulted in a net loss of LL. ${ }^{8}$ Nevertheless, patients in either the LIV $\geq$ L-5 or the LIV-ilium group failed to show significant improvement in postoperative cervical parameters. However, patients with an LIV $\geq$ L-5 had a postoperative loss of $15.3^{\circ}$ in LL.

In a subsequent subgroup analysis, we aimed to determine whether severe thoracic deformity was associated with reciprocal change. Although concrete thresholds for defining sharp angular sagittal TK have not been clearly defined, severe TK was represented by selecting patients with a maximum $\mathrm{TK} \geq 60^{\circ}$. In this cohort of 35 patients, the single observed change was a mean loss of $15.6^{\circ}$ in LL. No cervical changes were seen. Severe deformity was also estimated by analyzing only those patients who had undergone $3 \mathrm{CO}$ (38 patients), which is typically reserved for severe deformity and affords the appropriate surgical platform for inducing the greatest degree of correction. ${ }^{3}$ Application of the 3CO techniques, specifically VCR and PSO, for thoracic deformity correction has been described elsewhere. ${ }^{12,16,28,29}$ In this cohort of 38 patients, significant reciprocal improvements in cervical parameters were again absent, but as regards the lumbar parameters, there was $-7.8^{\circ}$ in LL. 
The explanation for the lack of reciprocal change in CL remains unclear. As Klineberg et al. posit, in much the same way that compensatory changes initially occur to preserve balance and horizontal gaze, alignment of regions distal to the correction site should similarly "recompensate" once focal correction is achieved ${ }^{8}$ Given that many of our patients were hyperlordotic in their cervical spine, it was expected that thoracic deformity correction would normalize the sagittal cervical Cobb angle. Our analysis revealed that the index surgery resulted in a significant change in TK, which would be expected to induce a reciprocal decrease in the T-1 slope (T1S) as well as a loss in CL to maintain horizontal gaze. However, while some reductions in T1S and CL were observed, they did not reach statistical significance.

There are several possible explanations for the failure of cervical alignment to compensate. First, we should note that in the population without fusion to the pelvis, a significant adjacent segment change (loss of lordosis) did occur in the lumbar spine. It is possible that this change is perhaps more likely to occur because of the greater impact of the lumbar area on overall global balance and energy expenditure. Second, the absence of change in the cervical spine may be a result of incomplete correction of the entire thoracic spine given a focus on apical (or sharp angle) kyphosis. Furthermore, given the difficulty in visualizing the T1-4 area on radiographic studies, it is possible that a compensatory increase in kyphosis occurred in the region. We were not able to visualize this area well enough to include T1-4 (upper TK) in our analysis. A lack of significant change in T1S may account for some of the absent reciprocal change as T1S and CL are closely related..$^{19} \mathrm{In}$ creases in T1S cause increases in CL if the patient is to maintain a horizontal gaze. ${ }^{19}$ Furthermore, although overall TK significantly decreased, the patients, on average, still had a large TK with a mean of $51.5^{\circ}$, and those with an initial maximum $\mathrm{TK} \geq 60^{\circ}$ had a mean of $56.3^{\circ}$ at 2 years. Thus, it is possible that the deformity correction was focused around the apical thoracic deformity, resulting in a decrease in the sharp angle but not as great an increase in overall TK and thus no change in T1S and continued elevation of CL.

It is also interesting to note the statistically significant increase in C2-7 SVA, which would translate to worsening cervical deformity. On average, patients increased in their cervical SVA, further confounding the anticipated favorable reciprocal change. As mentioned above, an incomplete correction of total TK or an increase in T1-4 kyphosis may have resulted in these persistent or worsened alignment values.

Overall, these findings highlight the importance of requisitioning full standing radiographs in the workup of patients with thoracic deformity. Preoperatively, many such patients also demonstrate cervical deformity. Importantly, the correction of TK does not normalize cervical alignment and may worsen cervical sagittal alignment. The strengths of the present study, compared with previous analyses, are its multiinstitutional nature and its accrual of a larger number of patients with thoracic deformity. ${ }^{8,17}$ However, these factors also pose limitations, as individual variations in the surgical technique or procedural bias may be present. Furthermore, the study's retrospective nature imposes inherent limitations. Future studies should emphasize the prospective collection and analysis of patient data, which would allow for more detailed analyses of the presence and types of reciprocal change that can occur following thoracic deformity surgery. In addition, EOS imaging may allow higher-definition imaging of changes in the T1-4 region often obscured by the shoulders and upper thorax. Correlation with patient outcomes and cervical health-related quality of life parameters could also prove to be an important issue to investigate in the future as well.

\section{Conclusions}

Dynamic reciprocal changes following corrective surgery for thoracic deformity have been largely unexplored to date. This multicenter analysis of a consecutive cohort of patients with ASD who were treated for thoracic deformity revealed that concurrent cervical malalignment is prevalent in this population and that cervical malalignment persists despite thoracic deformity correction. As a result, the evaluation of concomitant increased CL and cervical sagittal malalignment should be encouraged, and clinicians must be cognizant of the fact that, unlike in lumbar corrective surgery, the risk for persistent cervical malalignment remains high following selective correction of the thoracic deformity.

\section{References}

1. Angevine PD, Kaiser MG: Radiographic measurement techniques. Neurosurgery 63 (3 Suppl):40-45, 2008

2. Bess S, Boachie-Adjei O, Burton D, Cunningham M, Shaffrey C, Shelokov A, et al: Pain and disability determine treatment modality for older patients with adult scoliosis, while deformity guides treatment for younger patients. Spine (Phila Pa 1976) 34:2186-2190, 2009

3. Bridwell KH: Decision making regarding Smith-Petersen vs. pedicle subtraction osteotomy vs. vertebral column resection for spinal deformity. Spine (Phila Pa 1976) 31 (19 Suppl):S171-S178, 2006

4. Champain S, Benchikh K, Nogier A, Mazel C, Guise JD, Skalli W: Validation of new clinical quantitative analysis software applicable in spine orthopaedic studies. Eur Spine J 15:982-991, 2006

5. Glassman SD, Berven S, Bridwell K, Horton W, Dimar JR: Correlation of radiographic parameters and clinical symptoms in adult scoliosis. Spine (Phila Pa 1976) 30:682-688, 2005

6. Glassman SD, Bridwell K, Dimar JR, Horton W, Berven S, Schwab F: The impact of positive sagittal balance in adult spinal deformity. Spine (Phila Pa 1976) 30:2024-2029, 2005

7. Jang JS, Lee SH, Min JH, Maeng DH: Influence of lumbar lordosis restoration on thoracic curve and sagittal position in lumbar degenerative kyphosis patients. Spine (Phila Pa 1976) 34:280-284, 2009

8. Klineberg E, Schwab F, Ames C, Hostin R, Bess S, Smith JS, et al: Acute reciprocal changes distant from the site of spinal osteotomies affect global postoperative alignment. Adv Orthop 2011:415946, 2011

9. Lafage V, Ames C, Schwab F, Klineberg E, Akbarnia B, Smith J, et al: Changes in thoracic kyphosis negatively impact sagittal alignment after lumbar pedicle subtraction osteotomy: a comprehensive radiographic analysis. Spine (Phila Pa 1976) 37:E180-E187, 2012 
10. Lafage V, Schwab F, Patel A, Hawkinson N, Farcy JP: Pelvic tilt and truncal inclination: two key radiographic parameters in the setting of adults with spinal deformity. Spine (Phila Pa 1976) 34:E599-E606, 2009

11. Lafage V, Schwab F, Skalli W, Hawkinson N, Gagey PM, Ondra S, et al: Standing balance and sagittal plane spinal deformity: analysis of spinopelvic and gravity line parameters. Spine (Phila Pa 1976) 33:1572-1578, 2008

12. Lafage V, Smith JS, Bess S, Schwab FJ, Ames CP, Klineberg E, et al: Sagittal spino-pelvic alignment failures following three column thoracic osteotomy for adult spinal deformity. Eur Spine J 21:698-704, 2012

13. McAviney J, Schulz D, Bock R, Harrison DE, Holland B: Determining the relationship between cervical lordosis and neck complaints. J Manipulative Physiol Ther 28:187-193, 2005

14. Newton PO, Yaszay B, Upasani VV, Pawelek JB, Bastrom TP, Lenke LG, et al: Preservation of thoracic kyphosis is critical to maintain lumbar lordosis in the surgical treatment of adolescent idiopathic scoliosis. Spine (Phila Pa 1976) 35:1365-1370, 2010

15. O'Brien MF, Kuklo TR, Blanke KM, Lenke LG (eds): Spinal Deformity Study Group Radiographic Measurement Manual. Memphis, TN: Medtronic Sofamor Danek, 2005

16. O'Shaughnessy BA, Kuklo TR, Hsieh PC, Yang BP, Koski TR, Ondra SL: Thoracic pedicle subtraction osteotomy for fixed sagittal spinal deformity. Spine (Phila Pa 1976) 34:2893-2899, 2009

17. Peelle MW, Boachie-Adjei O, Charles G, Kanazawa Y, Mesfin A: Lumbar curve response to selective thoracic fusion in adult idiopathic scoliosis. Spine J 8:897-903, 2008

18. Rillardon L, Levassor N, Guigui P, Wodecki P, Cardinne L, Templier A, et al: [Validation of a tool to measure pelvic and spinal parameters of sagittal balance.] Rev Chir Orthop Reparatrice Appar Mot 89:218-227, 2003 (Fr)

19. Scheer JK, Tang JA, Smith JS, Acosta FL Jr, Protopsaltis TS, Blondel B, et al: Cervical spine alignment, sagittal deformity, and clinical implications. A review. J Neurosurg Spine 19:141-159, 2013

20. Schwab F, Dubey A, Pagala M, Gamez L, Farcy JP: Adult scoliosis: a health assessment analysis by SF-36. Spine (Phila Pa 1976) 28:602-606, 2003

21. Schwab F, Lafage V, Patel A, Farcy JP: Sagittal plane considerations and the pelvis in the adult patient. Spine (Phila Pa 1976) 34:1828-1833, 2009

22. Schwab F, Patel A, Ungar B, Farcy JP, Lafage V: Adult spinal deformity-postoperative standing imbalance: how much can you tolerate? An overview of key parameters in assessing alignment and planning corrective surgery. Spine (Phila Pa 1976) 35:2224-2231, 2010
23. Smith JS, Fu KM, Urban P, Shaffrey CI: Neurological symptoms and deficits in adults with scoliosis who present to a surgical clinic: incidence and association with the choice of operative versus nonoperative management. J Neurosurg Spine 9:326-331, 2008

24. Smith JS, Shaffrey CI, Fu KM, Scheer JK, Bess S, Lafage V, et al: Clinical and radiographic evaluation of the adult spinal deformity patient. Neurosurg Clin N Am 24:143-156, 2013

25. Smith JS, Shaffrey CI, Lafage V, Blondel B, Schwab F, Hostin R, et al: Spontaneous improvement of cervical alignment after correction of global sagittal balance following pedicle subtraction osteotomy. J Neurosurg Spine 17:300-307, 2012

26. Tang JA, Scheer JK, Smith JS, Deviren V, Bess S, Hart RA, et al: The impact of standing regional cervical sagittal alignment on outcomes in posterior cervical fusion surgery. Neurosurgery 71:662-669, 2012

27. Villavicencio AT, Babuska JM, Ashton A, Busch E, Roeca C, Nelson EL, et al: Prospective, randomized, double-blind clinical study evaluating the correlation of clinical outcomes and cervical sagittal alignment. Neurosurgery 68:1309-1316, 2011

28. Wang Y, Lenke LG: Vertebral column decancellation for the management of sharp angular spinal deformity. Eur Spine J 20:1703-1710, 2011

29. Yang BP, Ondra SL, Chen LA, Jung HS, Koski TR, Salehi SA: Clinical and radiographic outcomes of thoracic and lumbar pedicle subtraction osteotomy for fixed sagittal imbalance. J Neurosurg Spine 5:9-17, 2006

30. Youssef JA, Orndorff DO, Patty CA, Scott MA, Price HL, Hamlin LF, et al: Current status of adult spinal deformity. Global Spine J 3:51-62, 2013

\section{Author Contributions}

Conception and design: Ames. Acquisition of data: Lafage. Analysis and interpretation of data: Oh, Scheer, Ames. Drafting the article: Oh, Scheer. Critically revising the article: Oh, Scheer, Eastlack, Smith, Lafage, Bess, Schwab, Ames. Reviewed submitted version of manuscript: all authors. Approved the final version of the manuscript on behalf of all authors: Oh. Statistical analysis: Oh. Study supervision: Ames.

\section{Correspondence}

Taemin Oh, Department of Neurological Surgery, Northwestern University, Feinberg School of Medicine, 676 N. St. Clair St., Ste. 2210, Chicago, IL 60611. email: taemin.oh87@gmail.com. 